\title{
Going beyond the use of internet in a village in the Amazon region
}

\author{
Debora Leal \\ University of Siegen \\ Siegen, 57068, Germany \\ debora.dleal@uni-siegen.de
}

\author{
Volker Wulf \\ University of Siegen \\ Siegen, 57068, Germany \\ volker.wulf@uni-siegen.de
}

\begin{abstract}
In this paper I briefly describe my ongoing $\mathrm{PhD}$ work. Together with a rural community in the Brazilian Amazon I study their use patterns of internet applications and jointly improve the technical internet infrastructure in this remote area. My work serves to support their desire for increased resilience, and sheds light on how the culture of a technology and the culture of its recipients meet and how processes of adaption can be supported by HCI researchers.
\end{abstract}

\section{Author Keywords}

Amazon; infrastructure; internet use; resilience.

\section{ACM Classification Keywords}

K.4.m Computers and Society: Miscellaneous

\section{INTRODUCTION}

Much of the Brazilian Amazon region is remote and unconnected in several ways. There are hardly any paved roads and travel and transportation often happens by boat. In 2010, only 61,5 percent of the population in the North of Brazil had electricity in their homes [17]. It is also difficult to access basic health services, which is reflected in the sad fact that 14 percent of children die before the age of 1 [23]. Families are deprived of sewage treatment, clean water and most of public services. Much of the area also lacks connectivity to telecommunications including access to mobile networks or the internet. Government programs aim to increase electricity coverage through solar power, roads are being built (for which the forest needs to be cut down) and several projects also bring TV and telecommunication access. All of this is affecting local practices and relations. There is an increased pressure to look for work and education outside of the rural areas, which increases migration to cities. This weakens personal ties between community members, at the same time that make the use of internet a necessity for social and economic reasons.

\footnotetext{
Permission to make digital or hard copies of all or part of this work for personal or classroom use is granted without fee provided that copies are not made or distributed for profit or commercial advantage and that copies bear this notice and the full citation on the first page. Copyrights for components of this work owned by others than the author(s) must be honored. Abstracting with credit is permitted. To copy otherwise, or republish, to post on servers or to redistribute to lists, requires prior specific permission and/or a fee. Copyright 2018 SBC.
}

IHC 18, Anais Estendidos do XVII Simpósio Brasileiro sobre Fatores Humanos em Sistemas Computacionais

Outubro 22-26, 2018, Belém, Brazil

WTD-IHC

\section{RESEARCH GOAL AND PROBLEM DEFINITION}

Since 2015 I work in partnership with the Association of Organic Farmers of Boa Vista (APOBV), a small rural community near the city of Belem, about forty minutes by boat from a small local harbour. Boa Vista has an estimate of two hundred families that uses the land in a mostly informal economy in relationship with the surrounding forest.

Through our joint work I have witnessed the dilemma they find themselves in: stuck between their traditional way of live and a development that includes the advent of roads, electricity, globalized markets and the internet. Throughout the past years several members have repeatedly expressed their wish for their traditional ways to remain and for their community to be strong.

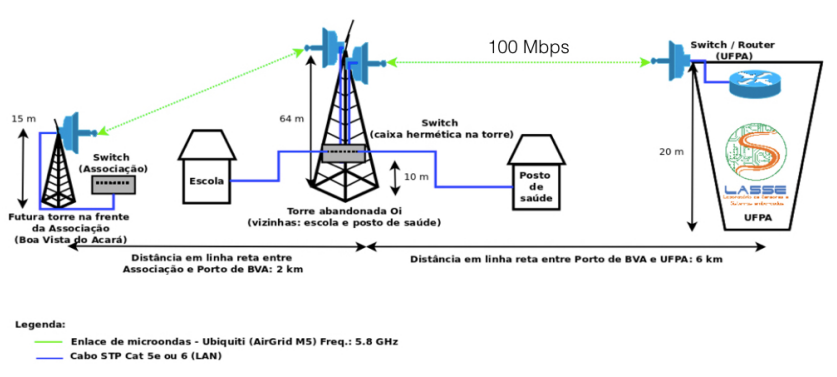

Figure 1. Sketch showing how an internet signal is transmitted from UFPA in Belem to the community of Boa Vista do Acara.

Amongst other activities, we developed a project to bring internet to the community. Acara remains largely unconnected and the region suffers with limited mobile network coverage with limited ways to communicate. An important aspect of this work was to provide access and the community be able to govern internet access as well as the ways it would be used. Their three main arguments to have internet signal were to call rescue, educational purpose for younger generations, and for business transactions. The association also developed plans of expanding the activities to create other business arrangements. My work focusses both on use patterns of the internet, as well as jointly developing the necessary infrastructure for it. Figure 1 shows the setup of the infrastructure the community of Boa Vista do Acara and me have developed together with the Technological Institute of Aeronautics in Sao Paulo and the Federal University of Para in Belem, specifically their Lasse lab: a signal is provided from the city of Belem, arriving in the harbour on the other side of the river. From there it is distributed to the community 
through the surrounding forrest via a network of towers and antennas. While technologically not complicated, the local conditions, e.g. nature and instability of electricity interfere with its proper functioning, and frequent maintenance is required. Such maintenance relies on the availability of knowledge, time and motivation, which need to be organised and is the actual challenge.

In this process, my goals are also to go through dialogue and a reflective process that is embedded in the social relationships we have and done by understanding the history, culture, and local context: when I converse with a member of the community about aspects of their life, we both reflect and change our understanding of it. My questions serve as an opportunity for reflection, as their answers and questions for me. Based on Freire's experience, this process of dialogical reflection is empowering and leads to people having increased control over their own lives [13]. Moacir Gadotti, founder of the Paulo Freire Institute, says that dialogue is not only the encounter of two or more bits of knowledge but an encounter that takes place in praxis (action and reflection) in a social and political transformational commitment [14]. In line with this, my work not only aims to gather knowledge about the community of Acara, but is committed to being engaged with their concerns, and to be a resource to the community and its members. Creating a learning process environment for both of us.

\section{RELATED WORKS - WHEN THE INTERNET IS NEW}

Internet technology has rapidly expanded and reached most regions of the globe. However, many corners still remain unconnected. Numerous initiatives and strategies have been deployed to connect the unconnected, which allows me to look back on a significant amount of scholarly work. An early approach was the development of so-called telecenters [15], used for education, communication, economic activities or personal development [19]. Telecenters have been established across the globe in Latin America, Asia and Africa. Despite their popularity with donors and trendiness at the time telecenters have been largely a failure: the reasons include political barriers, financial unsustainability, a lack of customer service and content that was not relevant for the user groups. $[3,24]$

When it comes to accessing the internet, mobile phones have taken the spotlight in recent years. In Africa it has affected health, social relations, economic practices [1], and has overall decreased inequality [2]. Even though this has been termed a mobile revolution by various authors and actors including the World Bank [8, 22], a recent study by Csikszentmihaily et al [7] has shown that the costs of accessing internet through cellphone is in many African countries prohibitively high.

Both Google and Facebook have launched prominent projects to improve internet access in regions of the world where connectivity is low. Facebooks Free Basics delivers access to a selected part of the internet through an app [21]. The initiative has been met with a great amount of criticism for violating net neutrality [21], and as a response India has withdrawn from the program [5]. Google launched a project that aims to provide free access in the Amazon through a network of high-altitude balloons [18].

Governments of developing countries have also undertaken steps to provide internet access to its citizens. An interesting example of this is Cuba's initiative to provide access to low-bandwidth WiFi in a few selected parks across the country [10]. Several initiatives across the world are started and led by civic actors, activist networks and NGOs. A prominent example of this is the Freifunk network that provides free access to Internet via WiFi in several German cities [12]. Initiatives for internet infrastructure exist in other parts of the world: Rhizomatica and Coolab work to provide infrastructure and training in remote areas $[20,6]$.

It is however interesting to note that providing access alone is in some cases not enough: a study found that even in times of mobile access users value shared physical spaces such as libraries to access the internet for the services they provide such as staff assisting visitors to do research [9].

\section{METHODOLOGY}

My work draws from both Action Research as well as Participatory Design. I take an Action Research [16] approach to understand practices of internet use in Acara together with the community members. My insights are based on qualitative activities such as observations, conversations, interviews, formal and informal interactions. The research we do together is in the interest of the community: we shape our research questions together to gain a deeper understanding of the conditions the community lives in, including internet access, and ways to reach goals brought forward by the inhabitants. Community members are co-researchers rather than participants in this process. I also borrow methodologies from Grounded Theory, as my relationship with the community is extended over several years, includes long stays and frequent and informal interactions. Even though I am an outsider to Acara, over the years we have established friendships and are familiar with each other. I collect and analyse data simultaneously, and further inquiry is guided by themes as they emerge from my experiences.

The second methodological pillar of my work is Participatory Design (PD), as articulated by Bjrgvinsson et al. [4] and others. The political stance of PD to empower social groups such as workers [11] or marginalized urban youth [4] is suitable to the situation at hand where a rural community is not served by the stakeholders that supply the majority of the country (e.g. Telcos) and take measures into their own hands, on their own terms in ways that suit their specific wishes and cultural sensibilities.

In the collaboration between me and the community of Acara we therefore do not only aim to gain a deep understanding of the interaction between internet technology and the local culture, we also jointly formulate visions and desires for possible futures, develop the technical infrastructure such as a network of towers, antennas and routers and create specific practices that help to achieve the goals. Our joint design work takes many forms, from structured design meetings to more informal encounters and also incorporates workshops where we 
gain the necessary knowledge to install and maintain infrastructural components.

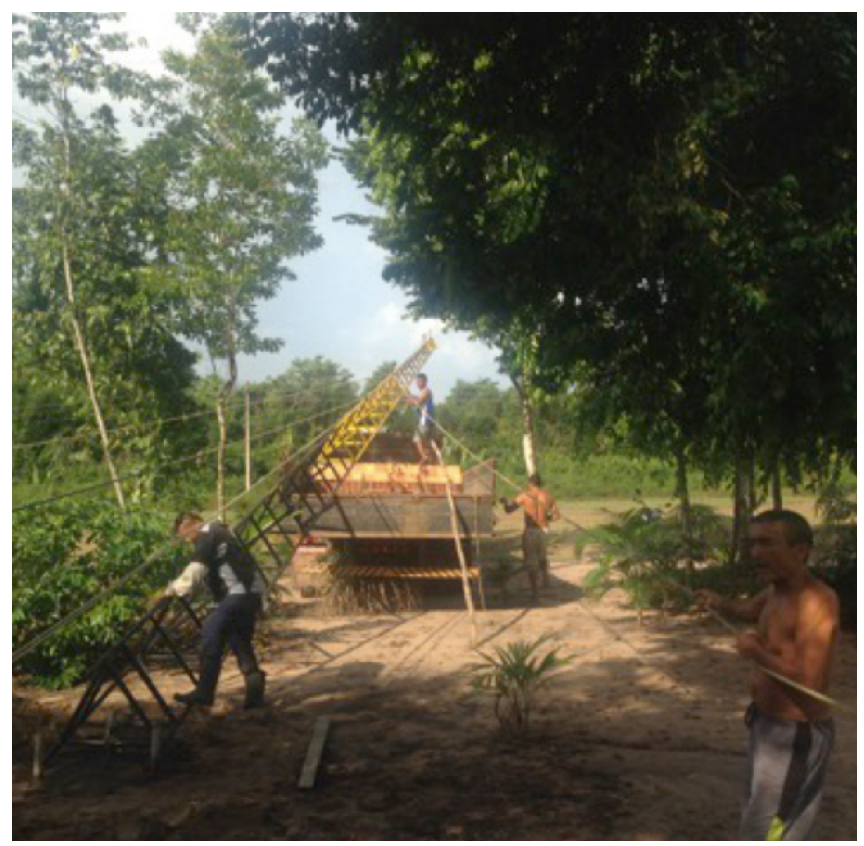

Figure 2. Installing the tower that carries the internet antenna in the center of the community.

Concretely, I collect data through observations which are recorded in field notes, interviews which I either record directly or take notes of later, depending on what the situation allows, and joint activities such as workshops, which provide a variety of outputs, from my own field notes to feedback, prototypes, and maps. The data is analysed together with my supervisor and other colleagues to identify the main themes.

\section{EXPECTED CONTRIBUTIONS OF THE WORK}

My academic work offers several contributions. The observations improve our understanding of the ways in which technologies arrive and are adapted in different cultural contexts, but also help us understand how HCI researchers can support such an adaption to local realities. Here I can already present a large number of valuable findings.

Internet in Acara has leveraged economic transactions, social interactions and learning engagement in the communities: Several members have established new business practices. A young man has opened a shop for religious clothing. He uses the internet to order stock from other state and takes pictures of specific clothes that he would like to sell, send to suppliers to inquire about availability and price. He also send pictures of new products to customers via Whatsapp to advertise. A group of women sells cosmetics through a similar setup. They take pictures of the makeup (some worn by themselves), publish on social media platforms and customers in the region can order the product or the service via direct messages. Since national post does not operate in the region they rely on a network of confidants to deliver the order. The logistics organised by the women provide an example of how local culture influences and IT use: e-commerce usually relies on the existence of specific infrastructure, such as a working postal system. Local realities and the absence of this infrastructure clash with the requirements of e-commerce: the houses in Acara do not have specific addresses, there are no mailboxes and post generally is not delivered by the national system in the village. In the absence of this infrastructure the women developed their own delivery mechanism which relies on trust existing between the inhabitants of the region.

The internet access also supports the political organization of the community. The association frequently deals with government institutions as well as cosmetics company that buys their natural products. They now use the internet to check, confirm or debunk information provided by them in these discussions, and thereby improve their position and power to influence negotiations in their favour. Also, a group of activists has formed, that call themselves The Group of Polemics, where information and opinions are shared with each other via messengers and once a week meet in person.

Besides the benefits observed, the internet is seeing as the bridge to fill the gap between education and a better life. A recently graduated woman in pedagogy says "internet is essential to my studies and work. We never stop studying in my area. It is so essential, that we are paying a very high price to have it."

My work also provides insights into how we can infrastructure the adaption of technologies by local actors, to strengthen local communities and increase resilience. We are currently focusing on jointly improving the internet infrastructure of Acara and are learning how to maintain it. In future steps we will review internet usage and develop practices that support previously expressed wishes of increased independence, strengthening of local culture and the ability to value lives within the community, without searching for education and work elsewhere. This effort is however not straightforward, and my research also sheds light on the complexities and complications arising from such work: all stakeholders, including the community, the local academic partner and myself bring their own goals, political stances and abilities, constraints and logics in which they operate to the project. Academic partners for example are perceived as generally more knowledgeable, even if their expertise does not extend into the practices of a local community. Such perceptions create hierarchies and power dynamics that influence (and likely inhibit) mutual participation. Likewise, after 15 years of expertise in software development I bring my own political views on the up- and downsides of technology, which might not always align with the goals of the community. In my work I pay attention to the configuration of partners and how the relationships between them - not just their specific sets of knowledge or material resources - influences the success or failure of a project.

\section{REFERENCES}

1. Aker, J. C., and Mbiti, I. M. Mobile Phones and Economic Development in Africa. Journal of Economic Perspectives 24, 3 (Aug. 2010), 207-232. 
2. Asongu, S. The impact of mobile phone penetration on African inequality. International Journal of Social Economics 42, 8 (2015), 706-716.

3. Best, M. L., and Kumar, R. Sustainability Failures of Rural Telecenters: Challenges from the Sustainable Access in Rural India (SARI) Project. Information Technologies and International Development 4, 4 (Oct. 2008), 31-45.

4. Bjorgvinsson, E., Ehn, P., and Hillgren, P.-A. Participatory design and democratizing innovation. In Proceedings of the 11th Biennial participatory design conference, ACM (2010), 41-50.

5. Cellan-Jones, R. India blocks Zuckerberg's free net app. BBC News (Feb. 2016).

6. Coolab. Coolab - Apoiar Capacitar Conectar, 2017. http: //www. coolab.org.

7. Csikszentmihalyi, C., Mukundane, J., Rodrigues, G. F., Mwesigwa, D., and Kasprzak, M. The Space of Possibilities: Political Economies of Technology Innovation in Sub-Saharan Africa. In Proceedings of the 2018 CHI Conference on Human Factors in Computing Systems, ACM (2018), 306.

8. Demombynes, G., and Thegeya, A. Kenya's mobile revolution and the promise of mobile savings. The World Bank, 2012.

9. Donner, J., and Walton, M. Your phone has internet-why are you at a library PC? Re-imagining public access in the mobile internet era. In IFIP Conference on Human-Computer Interaction, Springer (2013), 347-364.

10. Dye, M., Nemer, D., Pina, L. R., Sambasivan, N., Bruckman, A. S., and Kumar, N. Locating the Internet in the Parks of Havana. In Proceedings of the 2017 CHI Conference on Human Factors in Computing Systems, ACM (2017), 3867-3878.

11. Ehn, P. Work-oriented design of computer artifacts. $\mathrm{PhD}$ Thesis, Arbetslivscentrum, 1988.

12. Freifunk. Freifunk, May 2018. https ://en.wikipedia. org $/$ w $/$ index . php?title $=$ Freifunk $\&$ oldid $=840230770$.

13. Freire, P. Pedagogia do Oprimido, vol. 18. Paz e Terra, 1987.

14. Gadotti, M. Pedagogy of praxis: A dialectical philosophy of education. Suny Press, 1996.

15. Gomez, R. When you do not have a computer: Public-access computing in developing countries. Information Technology for Development 20, 3 (2014), 274-291.

16. Hayes, G. R. The relationship of action research to human-computer interaction. ACM Transactions on Computer-Human Interaction (TOCHI) 18, 3 (2011), 15.

17. IBGE. Censo Demografico 2010. Tech. rep., Instituto Brasileiro de Geografia e Estatistica, 2011.
18. ProjectLoon. Project Loon, 2018. https://x. company/loon/.

19. Reilly, K., and Gmez, R. Comparing approaches: telecentre evaluation experiences in Asia and Latin America. The Electronic Journal of Information Systems in Developing Countries 4, 1 (2001), 1-17.

20. Rhizomatica. Rhizomatica, 2018. https://www.rhizomatica.org/.

21. Sen, R., Ahmad, S., Phokeer, A., Farooq, Z. A., Qazi, I. A., Choffnes, D., and Gummadi, K. P. Inside the walled garden: Deconstructing facebook's free basics program. ACM SIGCOMM Computer Communication Review 47, 5 (2017), 12-24.

22. Steinbock, D. The mobile revolution: The making of mobile services worldwide. Kogan Page Publishers, 2005.

23. TheNatureConservancy. The Amazon Rainforest. Infographic, The Nature Conservancy, 2017.

https://www.nature.org/ourinitiatives/regions/ latinamerica/brazil/placesweprotect/ amazon-rainforest-infographic. xml.

24. Toyama, K., and Kuriyan, R. Review of research on rural PC kiosks. Microsoft Research India (2007). 